\title{
Lightweight Structural Concrete
}

\author{
Omnia Saad*, Khaled S. Ragab ${ }^{* *}$, Omar Elnawawy*, Yousef R. Alharbi ${ }^{* * *}$, Aref A. Abadel ${ }^{* * *}$, Abdalla Talaat*, $^{*}$ \\ Mohamed Kohail* \\ "Structural Engineering Department, Faculty of Engineering, Ain Shams University, Cairo, Egypt \\ "* Department of Civil Engineering, Housing and Building Research Centre, Cairo, Egypt \\ **** Department of Civil Engineering, College of Engineering, King Saud University, Saudi Arabia \\ Corresponding author: b.abdallaahmed@gmail.com
}

Submitted: $16-11-2020$

Revised: 26-11-2021

Accepted: 08-12-2021

\begin{abstract}
Using of Lightweight concrete (LWC) amounts to a lower cost and a better thermal performance due to its unique properties and light density. The main disadvantage in using lightweight concrete is that its mechanical properties are relatively poor. An effective method to improve the mechanical properties of lightweight concrete is using a dosage of nano-silica in the concrete mix. The gained enhancement of mechanical properties promotes a more serious discussion of structural applications of lightweight concrete. There exists an optimum dosage of nano-silica by which the mechanical properties enhancement is maximized. Increasing the nano-silica content beyond the optimum dosage degrades the mechanical properties. However, a fixed optimum dosage is not agreed upon in literature. This paper investigates the optimum dosage of NS to enhance the mechanical properties and microstructure of a lightweight concrete made with lightweight expanded clay aggregates (LECA). The results concluded that a dosage of $0.75 \%$ of nano-silica is optimum for the studied lightweight concrete mixes.
\end{abstract}

Keywords: Lightweight Aggregate Concrete (LWC), lightweight expanded clay aggregate (LECA), Nano-silica, optimum dosage, pore structure, apparent optimum NS dosage.

\section{INTRODUCTION}

Structural lightweight concrete (LWC) is a type of concrete with compressive strength higher than $17 \mathrm{MPa}$ and density lower than $1920 \mathrm{~kg} / \mathrm{m}^{3}$ (ACI, 2014). LWC has great thermal properties amounting to the large number of pores in its structure. Furthermore, the shrinkage behavior of LWC is different to normal concrete's; the internal curing mechanism occurring due to water being absorbed by lightweight aggregates (LWA) reduces concrete shrinkage as they act as water reservoirs(Lee et al., 2018). Also, using LWC reduces construction costs due to its lighter weight hence reducing the structural dead load. It is also a "relatively green"(Lo et al., 2007) material. The main disadvantage to using LWC as a structural material is low strength due to its pore structure. Consequentially, a lot of research has been conducted to improve the mechanical properties of LWC. Multiple problems have to be addressed before any significant structural application(Zhang et al., 2018). Silica fume (SF) is generally agreed on as a good additive for enhancing the properties of LWC(Mayhoub et al., 2020; Samson et al., 2017), even while achieving better results with normal concrete(Lincy et al., 2018; Mayhoub et al., 2020; Varghese et al., 2019).

A variety of fine materials are known to be used to enhance concrete properties like slag and fly ash, some are still recently discussed -volcanic pumice powder (Magbool and Zeyad, 2021a, 2021b), for example. Nano materials are also investigated for this purpose(Alharbi et al., 2021; Gamal et al., 2021; Silvestre et al., 2016; Sumesh et al., 2017), of which one of the most recent developments is the use of nano-silica (NS). Nano-silica was added to concrete mixes in dosages varying from $0.05 \%$ (Zhang et al., 2018) up to $10 \%$ (Vargas et al., 2018) to find the optimum percentage. A common observation is that: as the dosage of nano-silica increases, the concrete properties improved only up to a certain dosage which is usually the optimum percentage of NS for this particular mix. Exceeding the optimum dosage either demerit the mix or does nothing at all. The main issue, however, is that the optimum dosage of nano-silica varies with varying concrete mixes which makes it quite hard for standardizing the implementation of LWA in structural applications. This problem is rarely mentioned in the literature and focused research still does not exist for solving it. 
In the recent years, researchers have studied the effect of nano-silica on lightweight aggregate. This was done by introducing nano-silica into the concrete mix in varying dosages. Other mix design parameters were also varied. For example: slag cement(Heikal et al., 2013; Roychand et al., 2018; Zhang et al., 2012; Zhang and Islam, 2012) was used in manufacturing LWC instead of normal cement, and a variety of aggregates were used throughout the literature. LWC consists of three phases: the concrete matrix; the aggregates; and the cement/aggregate interfacial transition zone (ITZ)(Abd Elrahman et al., 2019). Nano-silica enhances LWC through multiple mechanisms: It fastens the rate of hydration, densifies the microstructure via filling the pores physically in addition to pozzolanic reactions producing C-SH gel(Abd Elrahman et al., 2019; Du et al., 2015; Saloma et al., 2015; Toropovs et al., 2014). This also increases the chloride resistance for LWC(Liu et al., 2011). Bleeding and segregation were observed as a side effect, but it occurred mostly in cases of self-compacting concretes(Cusson and Hoogeveen, 2008). Overall, the addition of nano-silica to LWC is beneficial, even more than silica fume(Afzali Naniz and Mazloom, 2018; Du et al., 2015; Varghese et al., 2019). Other side effects to adding NS to LWC include the need to increase the amount of superplasticizer and decrease the amount of stabilizer due to the increased viscosity of the fresh mix.

In this paper, experiments were conducted on mixes with varying nano-silica content to verify the optimum dosage of nano-silica to use in LWC containing lightweight expanded clay aggregate (LECA). Compressive and tensile tests were conducted, and the flexure behavior of reinforced beams was studied to determine the effect of NS on the mechanical properties of LWC. Durability tests were conducted as well. Furthermore, the microstructure of LWA was analyzed through scanning electron microscopy. Finally, the determination of the optimum NS dosage for mixes of different densities is discussed.

\section{MATERIALS AND METHODS}

\section{Material selection}

Normal cement of grade CEM I $\mid 52.5 \mathrm{~N}$ was used for the concrete mix. Most of the literature used normal cement, although some experiments were done using slag cement. The main fine aggregate is siliceous sand (Figure 1). Three coarse aggregates were tested, and one optimum aggregate was chosen to incorporate into the main mix design. For compressive and tensile specimens, a superplasticizer was used (Sika ViscoCrete-3425) to improve the workability of the mixes. For the nano-silica, its structure is presented through SEM in Figure 2. The chemical composition of NS is shown in Table 1. NS Dosages of $0.75 \%, 1.5 \%$, and $2 \%$ are used in the concrete mixes, along with a control mix having no NS.

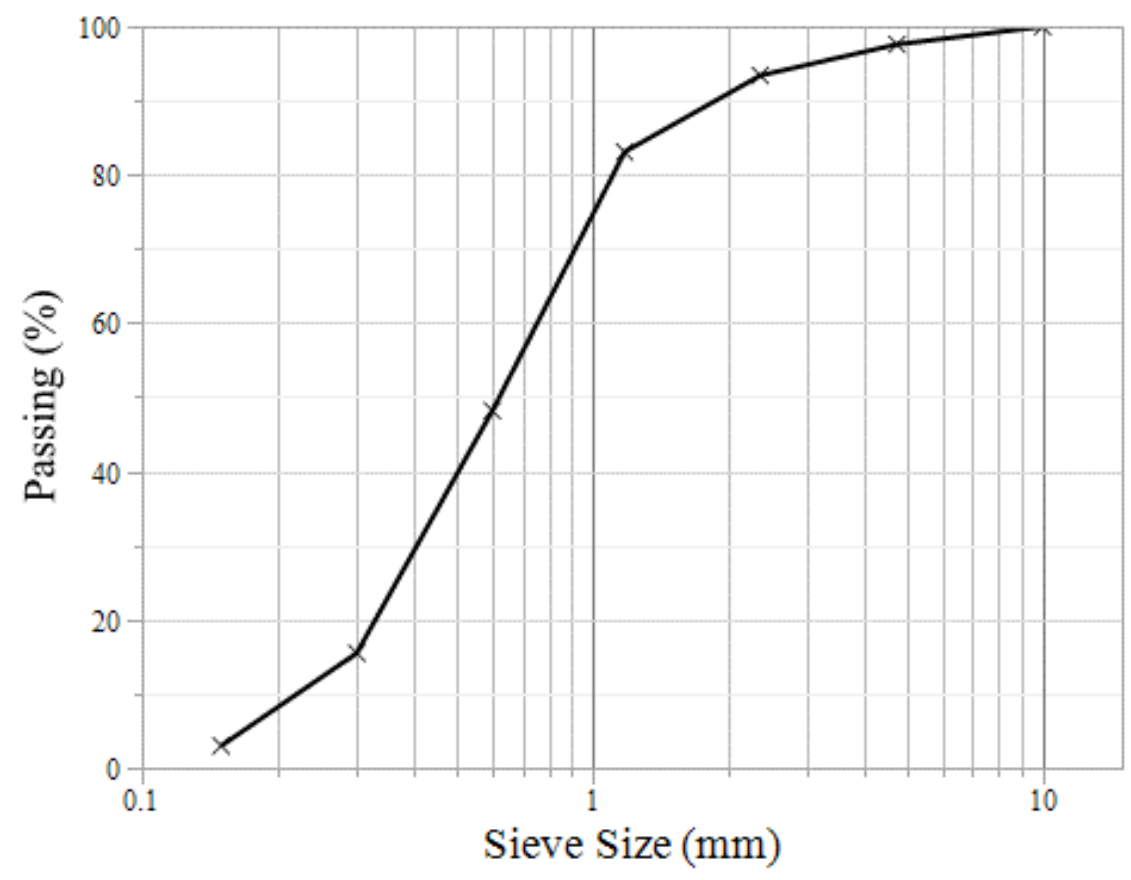

Figure 1. Sieve analysis of fine aggregates 
Table 1. Properties of nano-silica

\begin{tabular}{cccc}
\hline Diameter $(\mathbf{n m})$ & Purity & Surface Area $\left(\mathbf{m}^{\mathbf{2}} / \mathbf{g}\right)$ & Density $\left(\mathbf{g} / \mathbf{c m}^{\mathbf{3}}\right)$ \\
\hline 42 & $98 \%$ & 240 & 2.5 \\
\hline
\end{tabular}

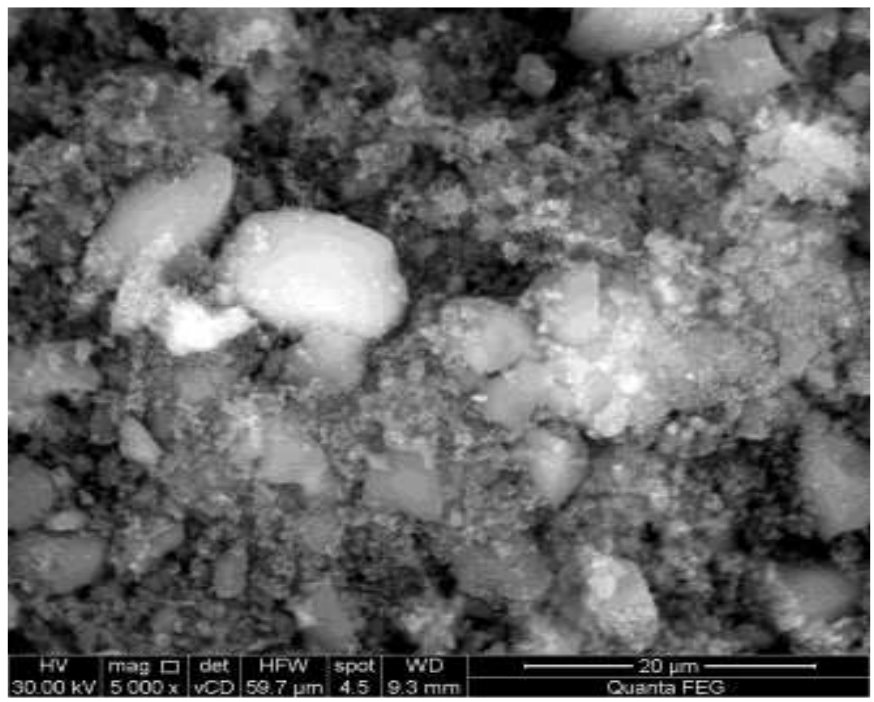

Figure 2. Microstructure of the used nano-silica through SEM

\section{Lightweight Aggregate}

Three types of lightweight aggregates have been evaluated for compressive strength and workability. LECA, lightweight sandal (Delta) block, and Kiment block were chosen for this preliminary testing. Designed mixes for each LWA are shown in Table 2. It was concluded that lightweight expanded clay aggregate was superior to the other LWAs (Figure 4), as it had the highest compressive strength and an acceptable density. Lightweight expanded clay aggregate is an inert substance produced from a plastic clay of very little lime content. The clay is dried, heated and burned in rotary kilns. LECA was explored extensively in the literature(Cusson and Hoogeveen, 2008; Rashad, 2018). Rashad(Rashad, 2018) highlighted that the use of LECA amounted to better ITZ and provided an array of practical applications. LECA can be incorporated into the mix design as coarse or fine aggregate, or both. Using LECA has many advantages regarding thermal resistance and workability, although it reduces mechanical strength and chloride resistance. The LECA used in this study is locally produced. Its density is $950 \mathrm{~kg} / \mathrm{m}^{3}$, and the particle sizes varied from $2.4 \mathrm{~mm}$ to $10 \mathrm{~mm}$.

Table 2. Mix proportions $\left(\mathrm{kg} / \mathrm{m}^{3}\right)$ for mixes containing different LWAs.

\begin{tabular}{lccccccccc}
\hline LWA & Cement & Water & Sand & LWA & S.P. & Limestone & Gravel & Density & wlc \\
\hline & 350 & 154.5 & 510 & 490 & 7 & - & - & 1638 & 0.44 \\
& 350 & 147 & 503 & 500 & 7 & - & - & 1560 & 0.42 \\
& 350 & 140 & 253 & 750 & 7 & - & - & 1405 & 0.40 \\
LECA & 350 & 140 & 433 & 570 & 7 & - & - & 1460 & 0.40 \\
\hline $\begin{array}{l}\text { Delta } \\
\begin{array}{l}\text { Block } \\
\text { (DB) }\end{array}\end{array}$ & 350 & 255 & 330 & 340 & 7 & 333 & - & 1750 & 0.73 \\
& 400 & 160 & 385 & 332 & 8 & 100 & 115 & 1734 & 0.40
\end{tabular}




\begin{tabular}{|c|c|c|c|c|c|c|c|c|c|}
\hline & 400 & 160 & 602 & 330 & 8 & - & - & 1700 & 0.40 \\
\hline & 350 & 140 & 328 & 350 & 7 & - & 325 & 2005 & 0.40 \\
\hline & 350 & 140 & 200 & 650 & 7 & - & 153 & 1770 & 0.40 \\
\hline Kiment & 350 & 140 & 153 & 750 & 7 & - & 100 & 1470 & 0.40 \\
\hline $\begin{array}{l}\text { Block } \\
\text { (KB) }\end{array}$ & 350 & 140 & 103 & 900 & 7 & - & - & 1365 & 0.40 \\
\hline
\end{tabular}

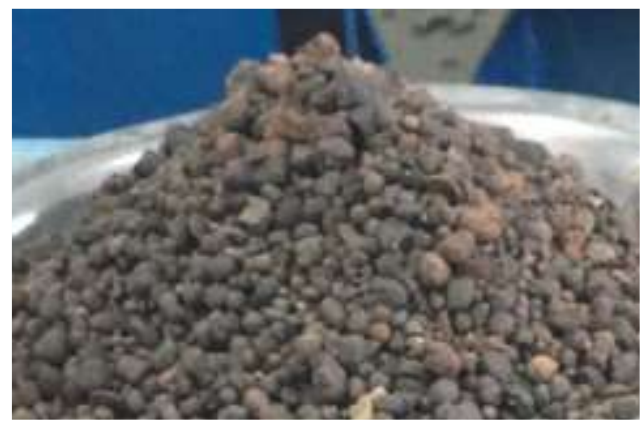

Figure 3. Locally produced LECA used in this study

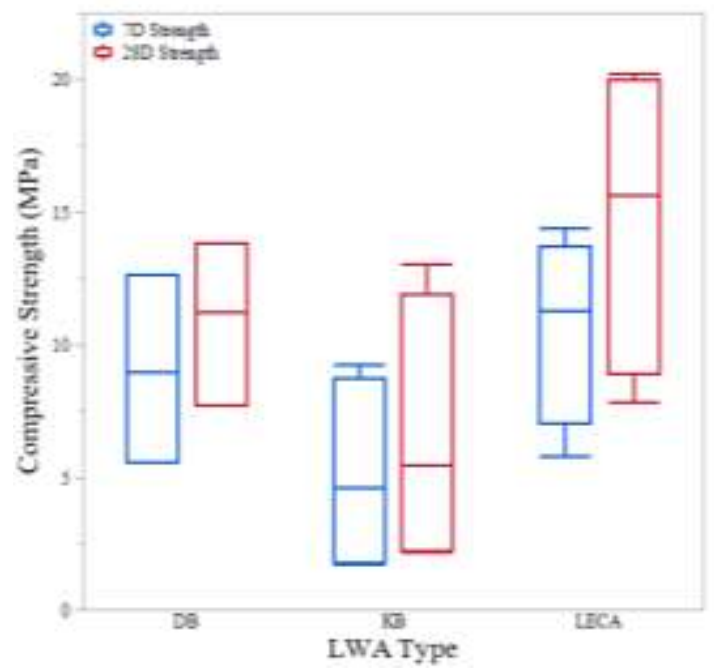

Figure 4. Compressive strength ( $7 \& 28$ days) for concrete mixes containing different LWA

\section{Mix design and experimental program}

Two mixing procedures were implanted, one for the specimens of compression and tension tests, and the other for the flexure beam specimens. Mixing, production, preparation and curing of the specimens is done according to standard practice for making and curing concrete test specimens in the laboratory (ASTM C 192 (ASTM, 2014)).

For the first mixing method, cement, fine aggregate, and NS were dry mixed for 2 minutes. Water was mixed with $\mathrm{SP}$ in an external pot, then it was added to the powder mix to mix for 5 minutes. Finally, the lightweight aggregate (LECA) was added to the mix and the components were mixed for 10 minutes. Concrete samples were poured in layers and compacted for (1 2) minutes by an automated vibrator. They are then kept in steel molds for 24 hours, after which they were cured in water at $23 \pm 2^{\circ} \mathrm{C}$ until testing. 
For the second method, the main difference is the method of introducing NS to the mix. Nano silica has been dissolved in $20 \%$ of the water before addition to the cement mixture. The dry constituents are mixed together first, then they are mixed with the remaining $80 \%$ of water. Finally, the nano-silica solution is added. LECA is the finally added to the mix before casting the concrete and compacting it by a free vibrator.

In order to assess the durability of the mixes, tests to determine the density, absorption, and the permeable pore structure (void \%) were performed in accordance with the standard (ASTM C642(ASTM, 2006)). Water sorptivity test was also executed in accordance with the standard (ASTM C1585(ASTM, 2004)). The standard specimen used is a disc of diameter $100 \pm 6 \mathrm{~mm}$ with a length of $50 \pm 3 \mathrm{~mm}$. Finally, abrasion tests were performed on cubic specimens of $70 * 70 * 70 \mathrm{~mm}$ cut from a 100*100*100mm cast in accordance with DIN 52108:2010-05(Normung), 2010).

Compressive strength is measured for $100 \mathrm{~mm} * 200 \mathrm{~mm}$ cylindrical specimens at ages 7,28 , and 90 days, three specimens at each age. It is generally accepted in the literature that cylindrical specimens yield more accurate results compared to cubic specimens(Talaat et al., 2020). The tensile strength is also determined through the splitting tensile strength test on 28 days aged cylindrical specimens $(100 \mathrm{~mm} * 200 \mathrm{~mm})$. For the first week of curing, the specimens are wet cured. They are then in dry air $23 \pm 2{ }^{\circ} \mathrm{C}$ and relative humidity $50 \pm 5 \%$. The designed mixes used for compressive and tensile strength are shown in Table 3.

Table 3. LWC mix design proportions $\left(\mathrm{kg} / \mathrm{m}^{3}\right)$ for mixes containing varying NS content

\begin{tabular}{cccccccccc}
\hline Mix & NS & Cement & Water & Sand & LECA & SP & wlc & Sand\agg & Mix Density \\
\hline NS000 & $0.00 \%$ & 350.00 & 140 & 433 & 570 & 7 & 0.4 & 0.76 & 1420 \\
NS075 & $0.75 \%$ & 347.35 & 140 & 433 & 570 & 7 & 0.4 & 0.76 & 1455 \\
NS150 & $1.50 \%$ & 344.75 & 140 & 433 & 570 & 7 & 0.4 & 0.76 & 1435 \\
NS200 & $2.00 \%$ & 343.00 & 140 & 433 & 570 & 7 & 0.4 & 0.76 & 1460 \\
\hline
\end{tabular}

The flexure behavior of LWC was assessed through testing reinforced specimens. It is important to note that some modifications to the mix design have been applied for this test, mainly: changing the cement content to $400 \mathrm{~kg} / \mathrm{m}^{3} \mathrm{instead}$ of $350 \mathrm{~kg} / \mathrm{m}^{3}$; and using another superplasticizer (MasterGlenium RMC 315). For the mixing process, NS was added to the concrete mix as a solution. Table 4 shows the mix design for this particular mix. It is important to note that the influence of NS on concretes with higher water content is more evident(Wasan et al., 2005) since the wlc ratio has been increased for these mixes. Specimens were formed from two mixes: a normal concrete mix; and a mix containing the apparent optimum dosage of NS - which is discussed in the following sections. The beam specimens were prepared for flexure testing, with concrete dimensions $\left(12 \mathrm{~cm}^{*} 16 \mathrm{~cm}^{*} 150 \mathrm{~cm}\right)$. Stirrups were chosen to be $7 \varphi 8 / \mathrm{m}^{\prime}$ to minimize shear interference. A steel reinforcement of $2 \varphi 12 / \mathrm{m}$ ' was placed for both top and bottom reinforcement of both beam specimens. Strain was monitored via multiple strain gauges mounted on the reinforcement steel.

Table 4. Mix design proportions $\left(\mathrm{kg} / \mathrm{m}^{3}\right)$ for mixes of flexure beams

\begin{tabular}{ccccccccc}
\hline Mix & NS & Cement & Water & Sand & LECA & SP & wlc & Sand\Agg \\
\hline NC & 0 & 400.00 & 180 & 700 & 500 & 8 & 0.5 & 1.40 \\
NS & 3 & 397.00 & 180 & 700 & 500 & 8 & 0.5 & 1.40 \\
\hline
\end{tabular}




\section{RESULTS}

\section{Mechanical behavior}

\section{Compressive and tensile strength}

The results of both compressive and tensile tests are shown in Table 5. The results show an improvement of strength from NS000 to NS075 due to the addition of $0.75 \%$ NS content. Increasing the NS content to $1.5 \%$ resulted in a decrement of both compressive and tensile strengths. From this data, it can be deduced that the optimum NS dosage is apparently $0.75 \%$ for this. However, further increment of the NS content to $2 \%$ resulted in a strength higher than that of the apparent optimum dosage.

Table 5. Results of compressive and tensile testing

\begin{tabular}{ccccc}
\hline & \multicolumn{3}{c}{ Compressive Strength } & Tensile Strength \\
Mix & 7 Days & 28 Days & 90 Days & 28 Days \\
\hline NS000 & 10.80 & 12.24 & 12.70 & 1.926 \\
NS075 & 12.48 & 16.08 & 17.98 & 2.372 \\
NS150 & 11.70 & 15.00 & 16.80 & 2.245 \\
NS200 & 12.12 & 15.48 & 18.50 & 2.786 \\
\hline
\end{tabular}

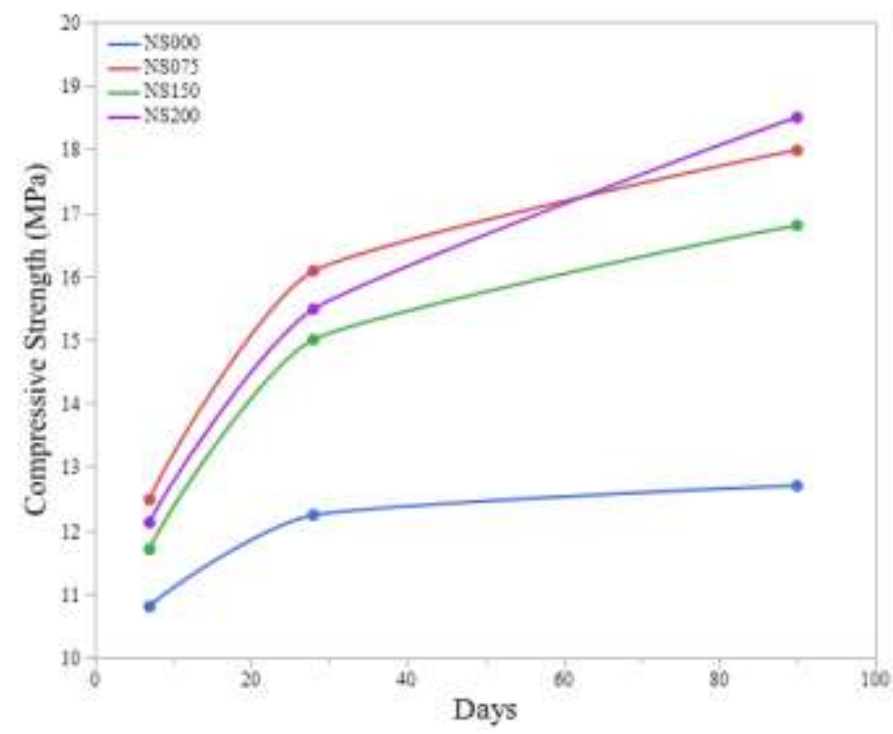

Figure 5. Compressive strength over time for mixes with varying NS content 


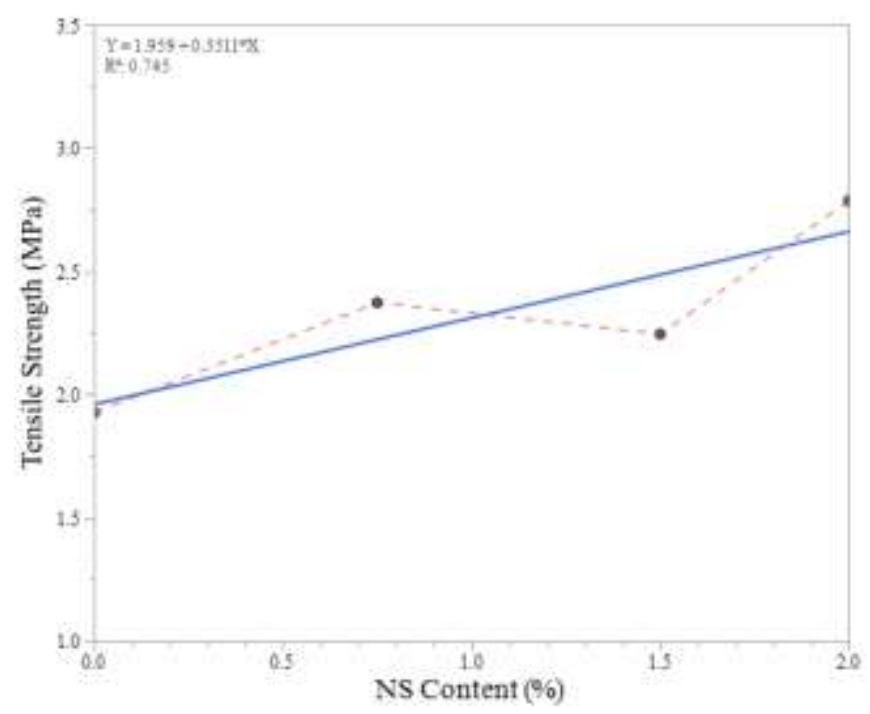

Figure 6. Splitting tensile strength over varying NS content

\section{Flexure of reinforced LWC beams}

The failure of the two specimens is shown in figures Figure 7 and Figure 8. The first crack level appeared in the NS beam at a load larger than that of the normal concrete beam. The first cracking deflections are $0.223 \mathrm{~mm}$ and $0.131 \mathrm{~mm}$, occurring at loads $0.98 \mathrm{kN}$ and $2.19 \mathrm{kN}$ for nano-silica and normal concrete beams respectively. The beams yielded at maximum crack width of $5.594 \mathrm{~mm}$ and $2.72 \mathrm{~mm}$ for nano-silica and normal concrete beams respectively. These results indicate a more ductile behavior for the beam incorporating nano-silica, as the load and deformation required to develop the first crack in the NS beam were almost doubled. The ultimate loads of both beams were similar, but the deflection of the normal concrete beam was deeper than that of the NS beam. The results clearly indicate that concrete mixes modified with the optimum dosage of NS have a better flexural behavior. Figure 9 shows the stress-strain for both beams. The maximum steel strain recorded by the strain gauges is $21 \mathrm{~mm}$ and $30 \mathrm{~mm}$ for NS and normal concrete respectively.

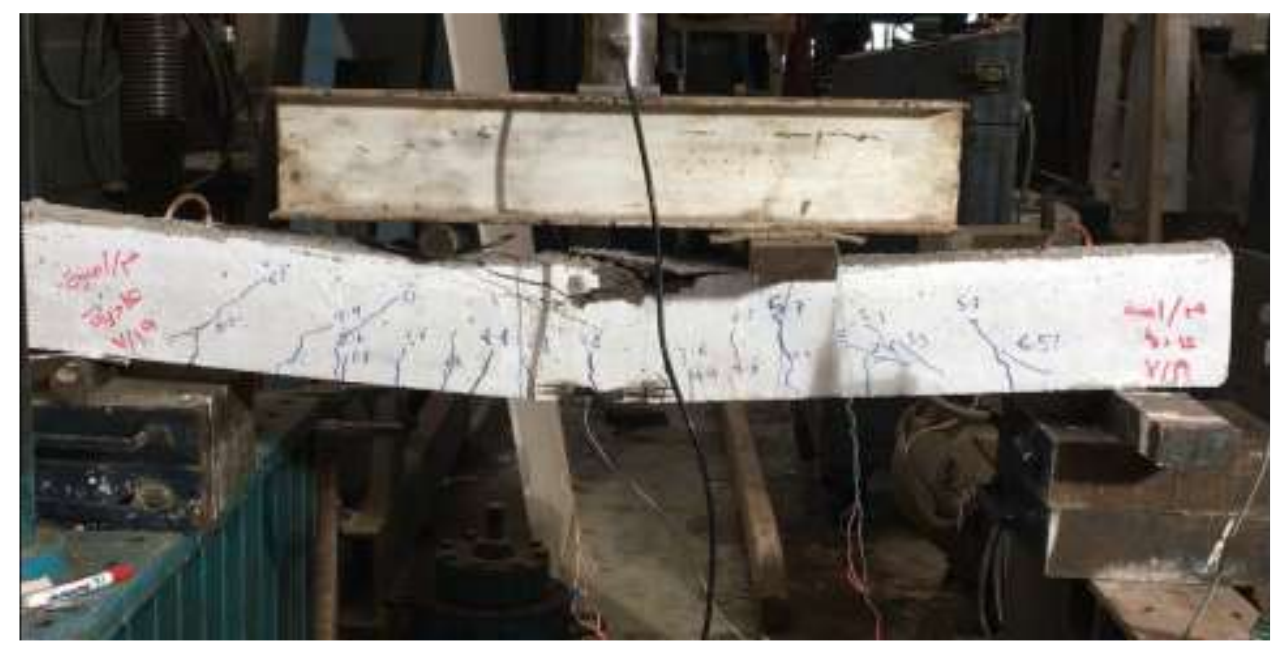

Figure 7. Failure of normal concrete beam under flexure 


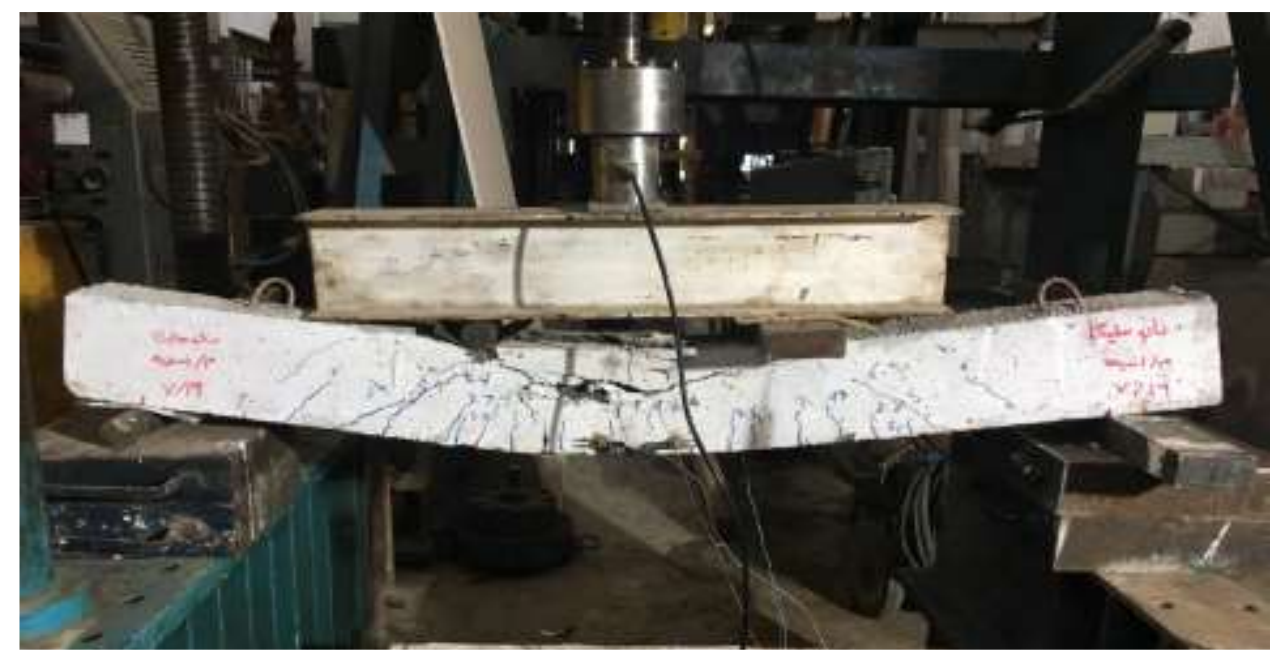

Figure 8. Failure of $0.75 \%$ NS concrete beam

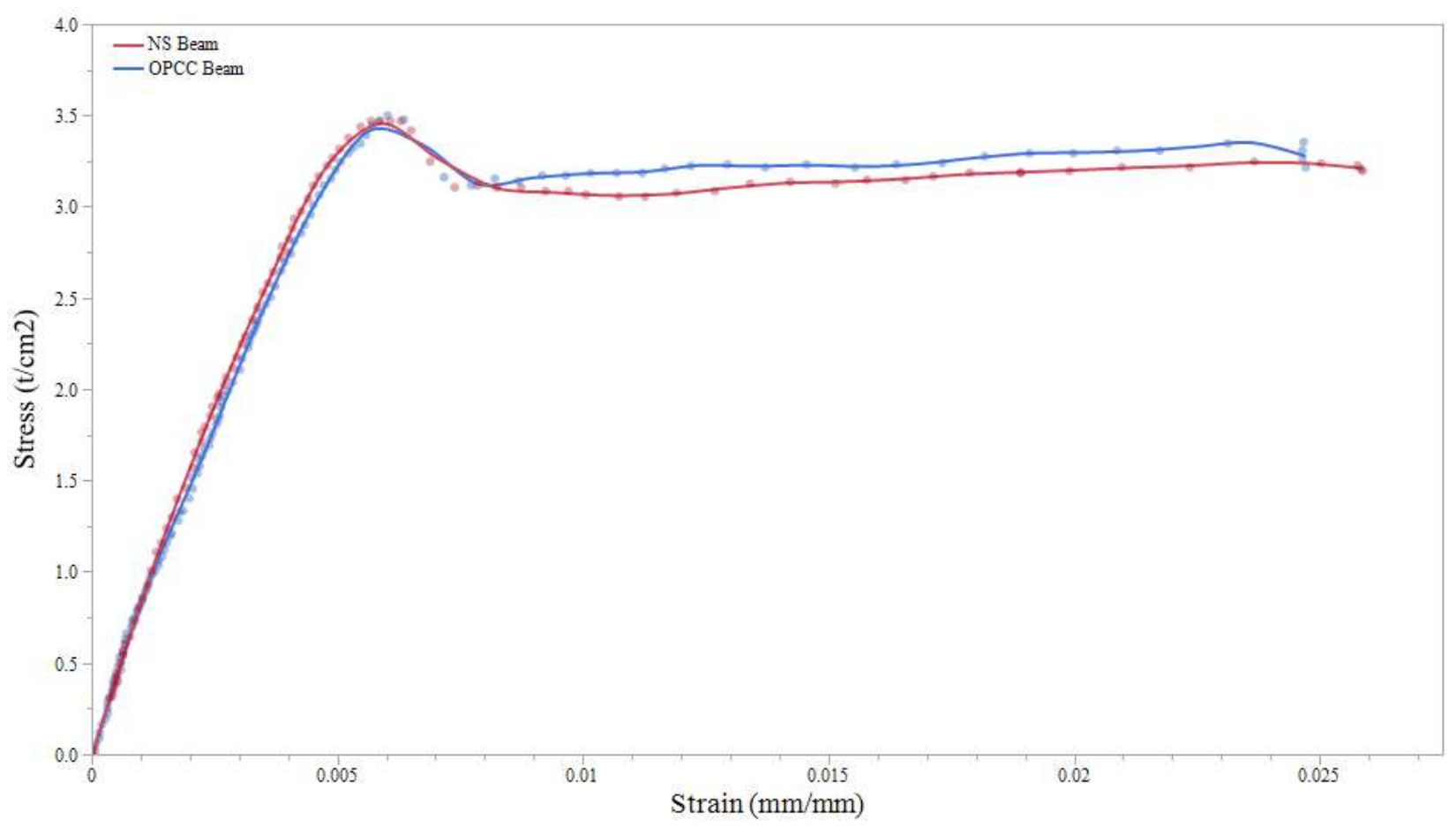

Figure 9. Stress strain behavior of flexure beams

\section{Durability assessment}

The void content and water absorption results are shown in Figure 10. The figure clearly shows the advantage of including NS into the mix compared to the control mix NS000. However, increasing the NS content beyond $0.75 \%$ had the opposite effect as it increased the permeable pore space and the water absorption. As for the water sorptivity test, Figure 11 shows a huge improvement for adding NS, especially NS075. For the other NS mixes (NS150 and NS200), it is evident that the pore structure of these mixes is a connected lattice crack. Finally, Figure 12 shows the results of abrasion tests. The results of this test also support those of the two previous tests, although the mix NS200 performed slightly better that NS075. Based on the durability tests alone, it is concluded that NS075 contains the optimum NS dosage $(0.75 \%)$. 


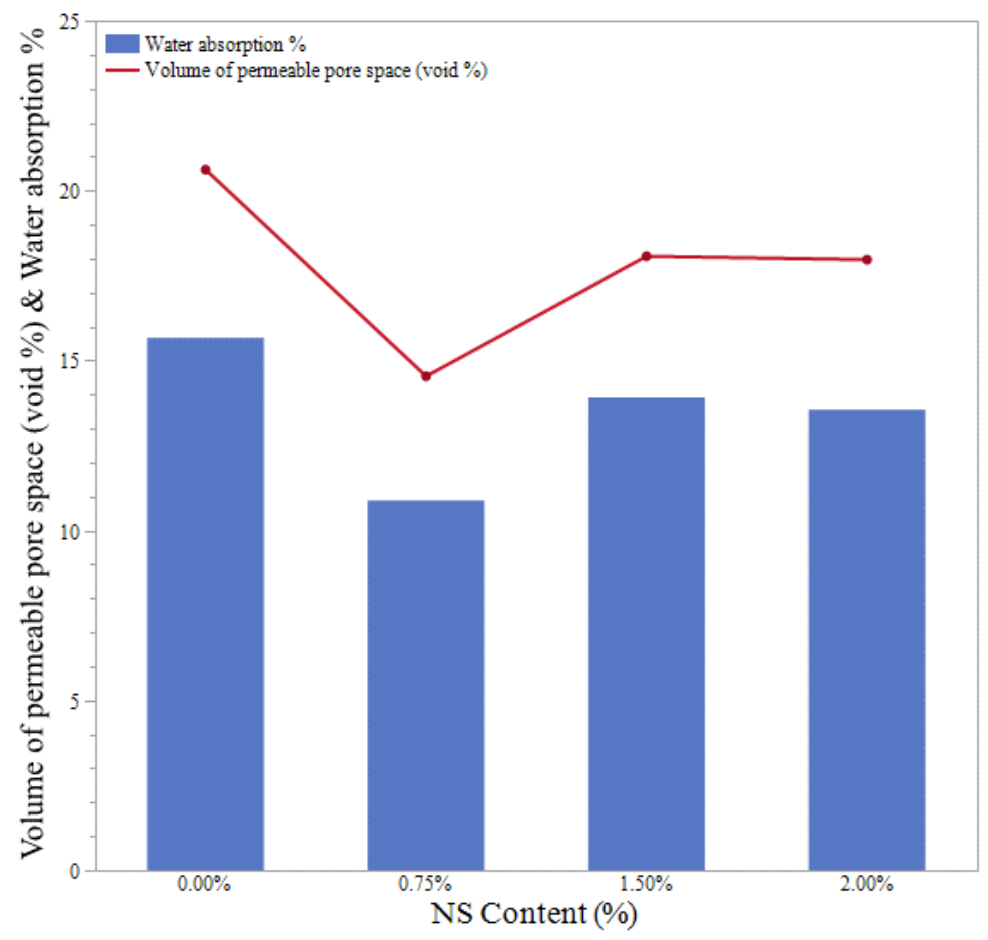

Figure 10. water absorption and permeable void content

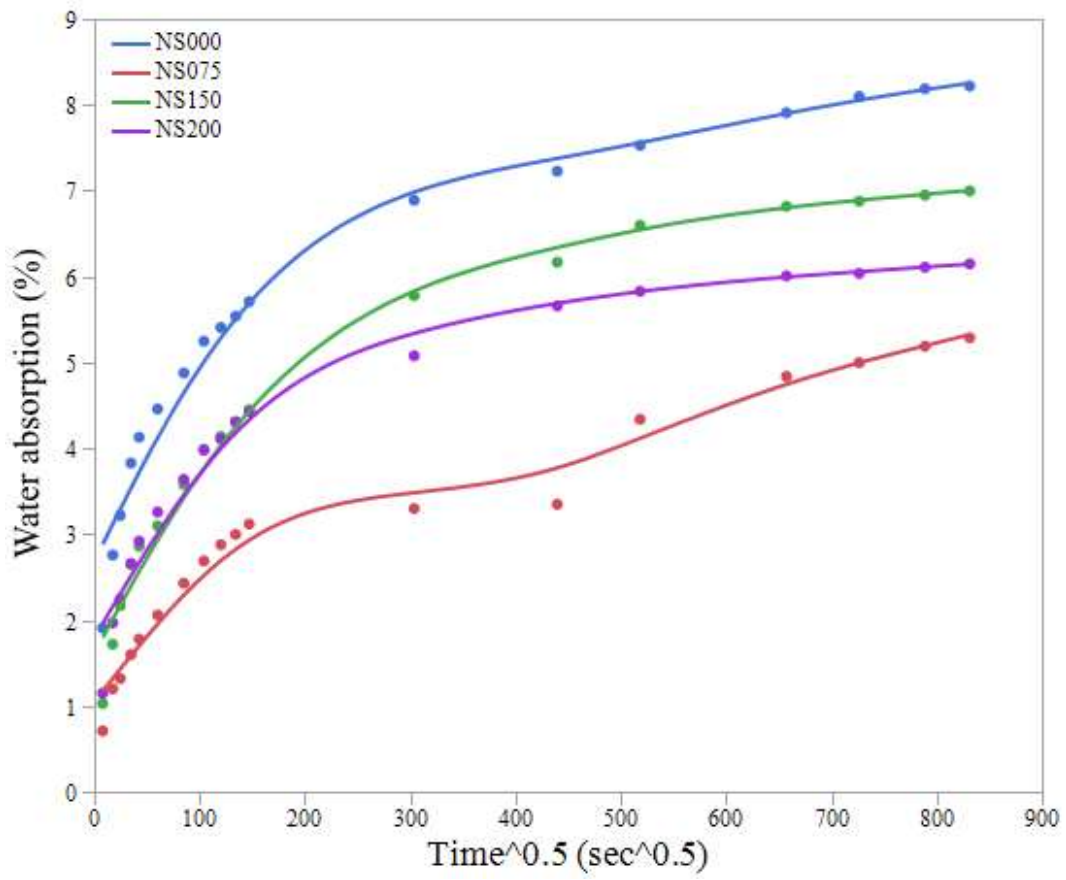

Figure 11. Water Sorptivity 


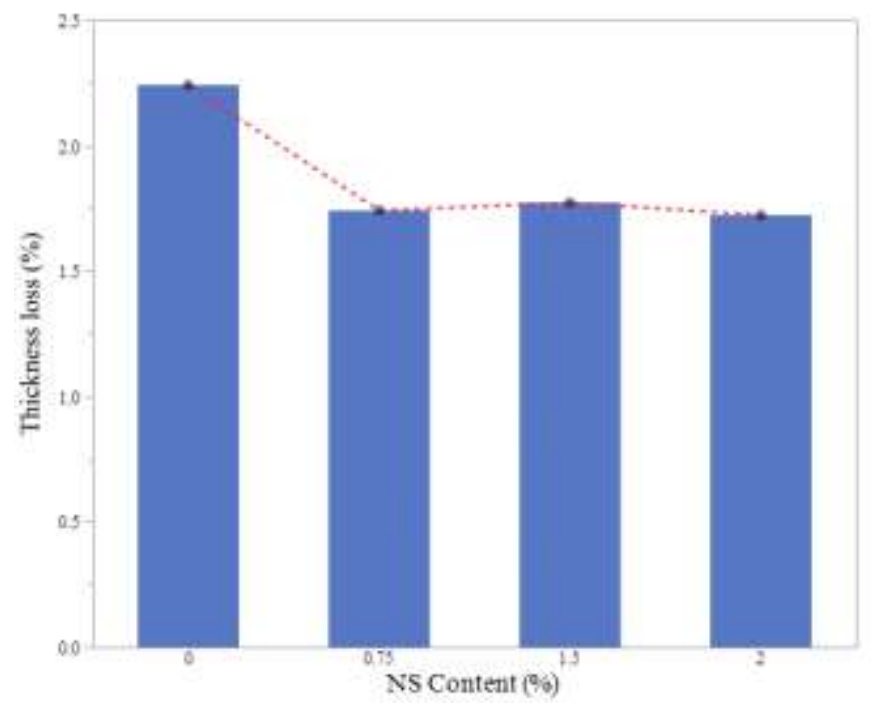

Figure 12. Thickness loss

\section{DISCUSSION}

\section{Microstructure}

The microstructure of the produced mixes is analyzed through a scanning electron microscope (SEM) as shown in Figure 13. Also, Figure 14 shows a higher magnification for the $1.5 \%$ and $2 \%$ NS mixes. It is clear that the $0 \%$ NS mix contains numerous larger pores relative to the other mixes. Another important observation is that for the mixes containing $1.5 \%$ and $2 \% \mathrm{NS}$, despite having less pores, the presence of cracks is evident. It is well stated that nanoparticles have a strong tendency to assemble around each other and agglomerate as a result of van der Waals forces(Wasan et al., 2005). NS exhibits a behavior similar to other nanoparticles like nano-clay(Bakr et al., 2019; Hamed et al., 2019; Maher El-Tair et al., 2020) or carbon nanotubes(Gamal et al., 2021); larger dosages of NS eventuate an agglomeration process as NS is very fine(Abd Elrahman et al., 2019; Sikora et al., 2020). Weak zones formed due to the agglomeration process induce microcracks rendering further increments in NS harmful or useless to the mix. Based only on durability tests, there is no ambiguity that the optimum dosage is $0.75 \%$ NS content. These results are supported by the SEM analysis.

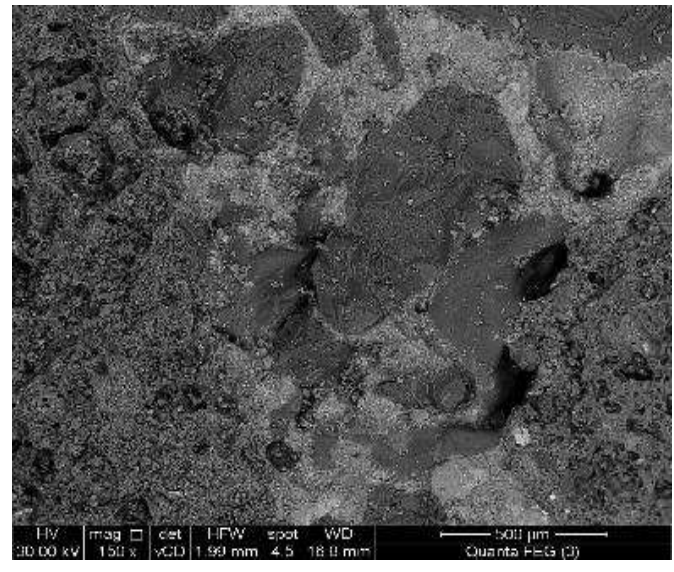

(a) $0 \%$ Nano-silica

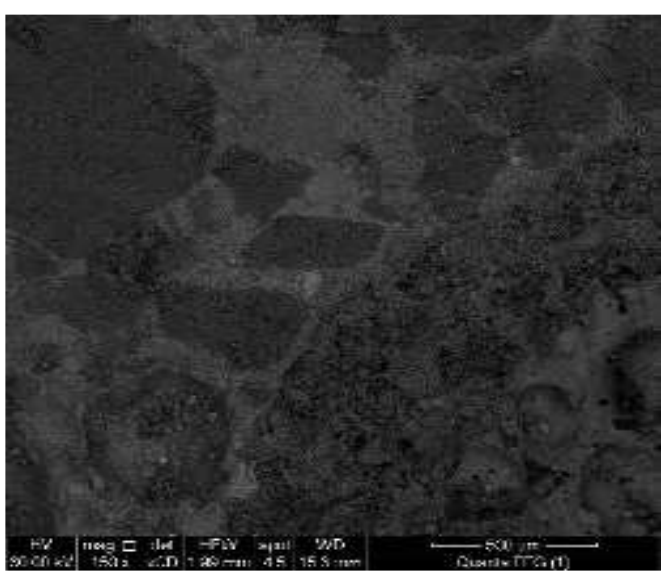

(b) $0.75 \%$ Nano-silica 


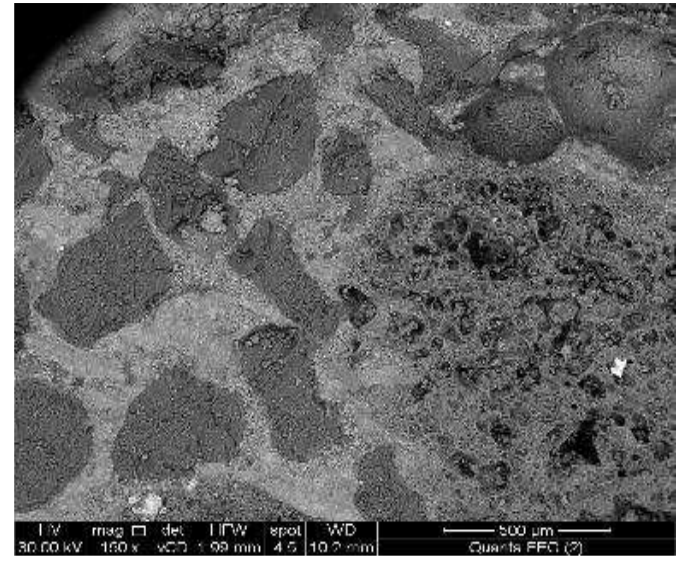

(c) $\quad 1.5 \%$ Nano-silica

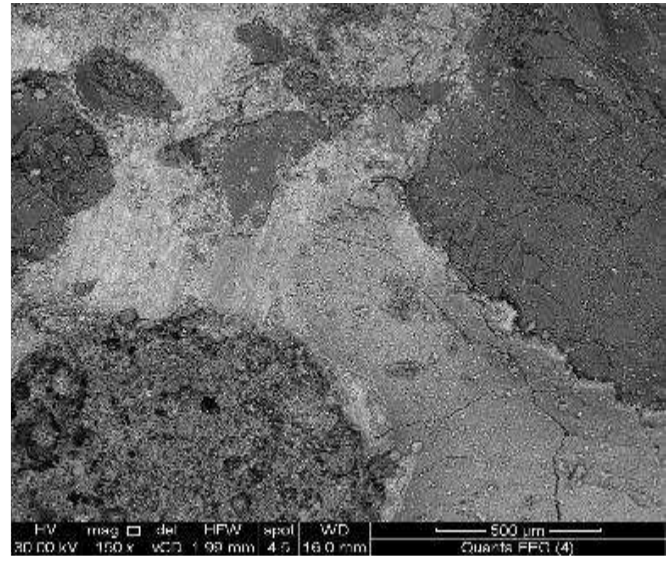

(d) $\quad 2 \%$ Nano-silica

Figure 13. SEM for the interfacial transition zone between the cement matrix and aggregates (150x)

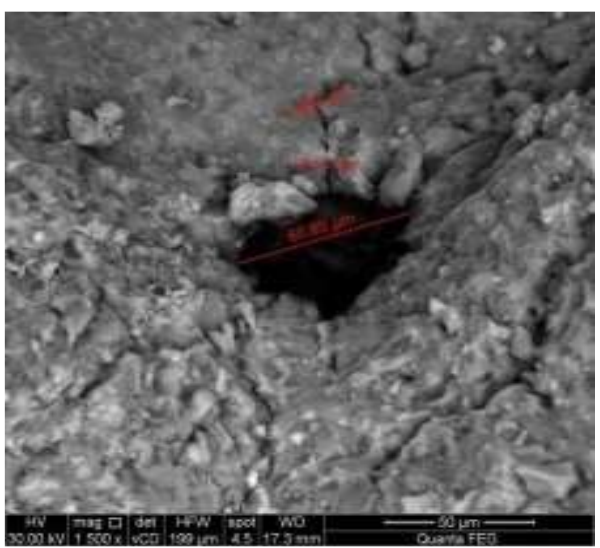

(a) $\quad 1.5 \%$ Nano-silica

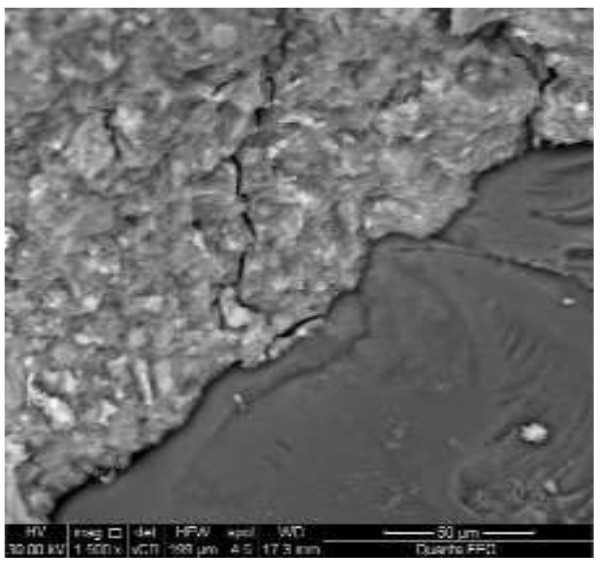

(b) $2 \%$ Nano-silica

Figure 14. Magnified SEM for mixes with higher NS content (1500x)

\section{Optimum Nano-Silica Dosage}

It is improbable that any further increment of NS content would continue to increase the mechanical properties. This is because any further increase in NS content will increase the agglomeration process leading to more microcracking. Thus, it was decided that the optimum NS content would be taken as the apparent optimum dosage. That is, the maximum NS dosage to produce an increment in mechanical properties after which a degradation of strength happens due to incrementing the NS content. The apparent optimum dosage could also be taken as the maximum NS dosage having nominal cracks, though this issue needs further investigation.

Another problem regarding the determination of the optimum NS dosage is the broad variability of the results of different studies. After investigating the results of several studies(Abd Elrahman et al., 2019; Afzali Naniz and Mazloom, 2018; Du, 2019; Sikora et al., 2020; Wang et al., 2018; Yu et al., 2015; Zhang et al., 2018) along this study, the optimum NS dosage seems to vary with varying LWC density (Figure 15). While there is an observed relation between the optimum NS dosage and the LWC density, various other factors should have an influence on the NS dosage. 


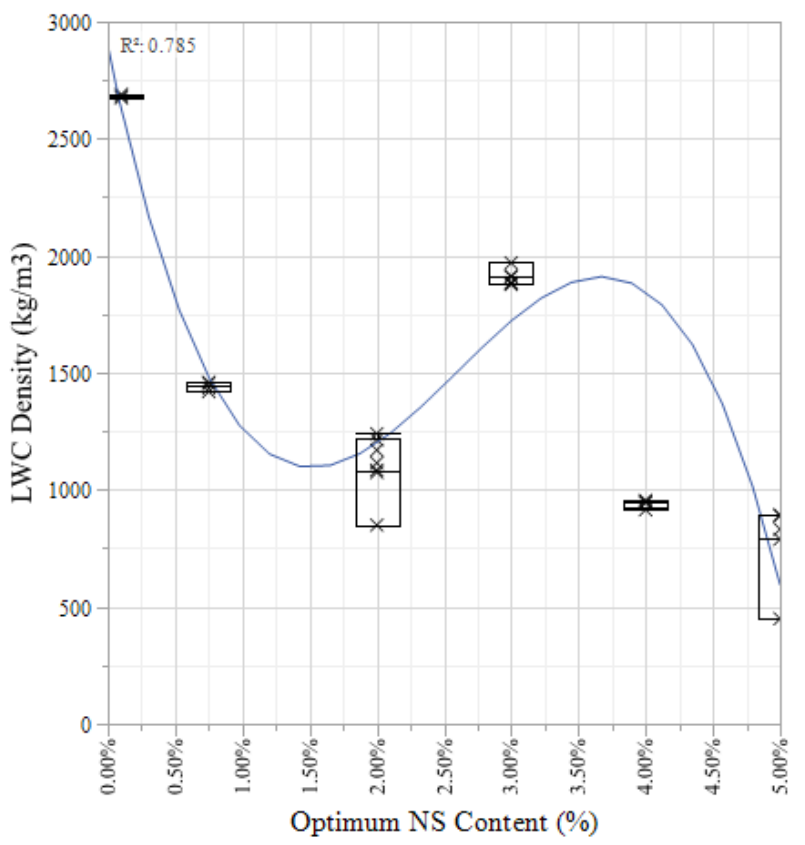

Figure 15. Apparent relation between LWC density and the optimum nano-silica content

\section{Practical Implications}

Compared to ordinary Portland cement concrete, lightweight concrete generally has worse mechanical properties but better thermal properties and lower density. Using lightweight concrete in structural elements is feasible as nano-silica significantly enhanced the mechanical properties of lightweight concrete.

\section{CONCLUSIONS}

The following conclusions are drawn based on the results of the conducted tests:

1. Comparing between three types of aggregates (Kiment, delta block and LECA), lightweight expanded clay aggregate proved to be the best in terms of density and mechanical performance.

2. The apparent optimum nano-silica dosage for the tested lightweight concrete mixes is $0.75 \%$.

3. Incorporating nano-silica into lightweight concrete enhanced its mechanical properties, durability, and microstructure. However, increasing the nano-silica dosage beyond the apparent optimum dosage might increase the mechanical properties.

4. Using nano-silica enhanced the flexural behavior as it yielded a more ductile failure and delayed the first cracking level. This is amounted to a better bond in the case of NS beam.

5. Increasing the nano-silica content beyond the apparent optimum dosage eventuates microcracks through agglomeration of the fine NS particles. So, absorption properties deteriorate albeit still being better than lightweight concrete without any nano-silica.

6. Various parameters affect the apparent optimum nano-silica dosage for a certain lightweight concrete, for example, the density of the lightweight aggregate used. Other factors like the specific surface area of NS may influence the apparent optimum dosage.

\section{Recommendations for Future Research}

More research should be focused on the effect of the density of LWA, LWC, and other variables on the optimum nano-silica dosage. Determining the effect of various factors on the apparent optimum NS dosage would give more confidence in nano-silica-modified LWC as a structural material. 


\section{ACKNOWLEDGEMENT}

The authors extend their appreciation to Researchers Supporting Project number (RSP-2020/271), King Saud University, Riyadh, Saudi Arabia.

\section{REFERENCES}

Abd Elrahman, M., Chung, S.-Y., Sikora, P., Rucinska, T., Stephan, D., 2019. Influence of Nanosilica on Mechanical Properties, Sorptivity, and Microstructure of Lightweight Concrete. Materials (Basel). $12,3078$. https://doi.org/10.3390/ma12193078

ACI, 2014. Guide for Structural Lightweight-Aggregate Concrete (ACI 213R-14). ACI Man. Concr. Pract. 1-58.

Afzali Naniz, O., Mazloom, M., 2018. Effects of colloidal nano-silica on fresh and hardened properties of self-compacting lightweight concrete. J. Build. Eng. 20, 400-410. https://doi.org/https://doi.org/10.1016/j.jobe.2018.08.014

Alharbi, Y.R., Abadel, A.A., Mayhoub, O.A., Kohail, M., 2021. Effect of using available metakaoline and nano materials on the behavior of reactive powder concrete. Constr. Build. Mater. 269. https://doi.org/10.1016/j.conbuildmat.2020.121344

ASTM, 2014. Standard Practice for Making and Curing Concrete Test Specimens in the Laboratory (ASTM C192 / C192M - 14). https://doi.org/https://doi.org/10.1520/C0192_C0192M-14

ASTM, 2006. Standard Test Method for Density, Absorption, and Voids in Hardened Concrete (ASTM C642 - 06). https://doi.org/10.1520/C0642-06

ASTM, 2004. Standard Test Method for Measurement of Rate of Absorption of Water by Hydraulic-Cement Concretes (ASTM C1585 - 04). https://doi.org/10.1520/C1585-04

Bakr, S.O., Mohamed, E.H., Raouf, N.E.A., Mohamed, K., 2019. Assessment of mechanical and fire resistance for hybrid nano-clay and steel fibres concrete at different curing ages. J. Struct. Fire Eng. 11, 189-203. https://doi.org/10.1108/JSFE-06-2019-0024

Cusson, D., Hoogeveen, T., 2008. Internal curing of high-performance concrete with pre-soaked fine lightweight aggregate for prevention of autogenous shrinkage cracking. Cem. Concr. Res. 38, 757-765. https://doi.org/https://doi.org/10.1016/j.cemconres.2008.02.001

Du, H., 2019. Properties of ultra-lightweight cement composites with nano-silica. Constr. Build. Mater. 199, 696-704. https://doi.org/https://doi.org/10.1016/j.conbuildmat.2018.11.225

Du, H., Du, S., Liu, X., 2015. Effect of nano-silica on the mechanical and transport properties of lightweight concrete. Constr. Build. Mater. 82, 114-122. https://doi.org/https://doi.org/10.1016/j.conbuildmat.2015.02.026

Gamal, H.A., El-Feky, M.S., Alharbi, Y.R., Abadel, A.A., Kohail, M., 2021. Enhancement of the concrete durability with hybrid nano materials. Sustainability 13, 1373.

Hamed, N., El-Feky, M.S., Kohail, M., Nasr, E.-S.A.R., 2019. Effect of nano-clay de-agglomeration on mechanical

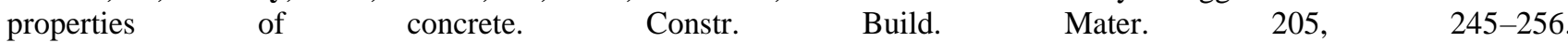
https://doi.org/https://doi.org/10.1016/j.conbuildmat.2019.02.018

Heikal, M., Abd El Aleem, S., Morsi, W.M., 2013. Characteristics of blended cements containing nano-silica. HBRC J. 9, 243-255. https://doi.org/10.1016/j.hbrcj.2013.09.001

Lee, K.-H., Yang, K.-H., Yoon, H.-S., 2018. Shrinkage strains of lightweight aggregate concrete using expanded bottom ash and dredged soil granules. Constr. Build. Mater. 188, 934-945. https://doi.org/https://doi.org/10.1016/j.conbuildmat.2018.08.168

Lincy, V., Rao, V.V.L.K., Lakshmy, P., 2018. A study on nanosilica- and microsilica-added concretes under different transport mechanisms. Mag. Concr. Res. 70, 1205-1216. https://doi.org/10.1680/jmacr.16.00504 
Liu, X., Chia, K.S., Zhang, M.-H., 2011. Water absorption, permeability, and resistance to chloride-ion penetration of lightweight aggregate concrete. Constr. Build. $\quad$ Mater. $335-343$. https://doi.org/https://doi.org/10.1016/j.conbuildmat.2010.06.020

Lo, T.Y., Tang, W.C., Cui, H.Z., 2007. The effects of aggregate properties on lightweight concrete. Build. Environ. 42, 3025-3029. https://doi.org/https://doi.org/10.1016/j.buildenv.2005.06.031

Magbool, H.M., Zeyad, A.M., 2021a. The effect of various steel fibers and volcanic pumice powder on fracture characteristics of Self-Compacting concrete. Constr. Build. Mater. 312, 125444.

Magbool, H.M., Zeyad, A.M., 2021b. The effect of varied types of steel fibers on the performance of self-compacting concrete modified with volcanic pumice powder. Mater. Sci.

Maher El-Tair, A., El-Feky, M.S., Sharobim, K.G., Mohammedin, H., Kohail, M., 2020. Improving the reactivity of clay nano-partciles in high strength mortars through indirect sonication method. Int. J. Sci. Technol. Res. 9, $1045-1054$.

Mayhoub, O.A., Nasr, E.-S.A.R., Ali, Y.A., Kohail, M., 2020. The influence of ingredients on the properties of reactive powder concrete: A review. Ain Shams Eng. J. https://doi.org/https://doi.org/10.1016/j.asej.2020.07.016

Normung), G.I. for S. (Deutsches I. für, 2010. TESTING OF INORGANIC NON-METALLIC MATERIALS - WEAR TEST USING THE GRINDING WHEEL ACCORDING TO BOHME - GRINDING WHEEL METHOD (DIN 52108:2010-05). Beuth Berlin.

Rashad, A.M., 2018. Lightweight expanded clay aggregate as a building material - An overview. Constr. Build. Mater. 170, 757-775. https://doi.org/https://doi.org/10.1016/j.conbuildmat.2018.03.009

Roychand, R., De Silva, S., Setunge, S., 2018. Nanosilica Modified High-Volume Fly Ash and Slag Cement Composite: Environmentally Friendly Alternative to OPC. J. Mater. Civ. Eng. 30, 04018043. https://doi.org/10.1061/(ASCE)MT.19435533.0002220

Saloma, Nasution, A., Imran, I., Abdullah, M., 2015. Improvement of Concrete Durability by Nanomaterials. Procedia Eng. 125, 608-612. https://doi.org/https://doi.org/10.1016/j.proeng.2015.11.078

Samson, G., Phelipot-Mardelé, A., Lanos, C., 2017. A review of thermomechanical properties of lightweight concrete. Mag. Concr. Res. 69, 201-216. https://doi.org/10.1680/jmacr.16.00324

Sikora, P., Rucinska, T., Stephan, D., Chung, S.-Y., Abd Elrahman, M., 2020. Evaluating the effects of nanosilica on the material properties of lightweight and ultra-lightweight concrete using image-based approaches. Constr. Build. Mater. 264, 120241. https://doi.org/https://doi.org/10.1016/j.conbuildmat.2020.120241

Silvestre, J., Silvestre, N., De Brito, J., 2016. Review on concrete nanotechnology. Eur. J. Environ. Civ. Eng. 20, 455485 .

Sumesh, M., Alengaram, U.J., Jumaat, M.Z., Mo, K.H., Alnahhal, M.F., 2017. Incorporation of nano-materials in cement composite and geopolymer based paste and mortar-A review. Constr. Build. Mater. 148, 62-84.

Talaat, A., Emad, A., Tarek, A., Masbouba, M., Essam, A., Kohail, M., 2020. Factors affecting the results of concrete compression testing: A review. Ain Shams Eng. J. https://doi.org/https://doi.org/10.1016/j.asej.2020.07.015

Toropovs, N., Bajare, D., Sahmenko, G., Krage, L., Korjakins, A., 2014. The Formation of Microstructure in High Strength Concrete Containing Micro and Nanosilica. Key Eng. Mater. $604, \quad 83-86$. https://doi.org/10.4028/www.scientific.net/KEM.604.83

Vargas, P., Marín, N.A., Tobón, J.I., 2018. Performance and Microstructural Analysis of Lightweight Concrete Blended with Nanosilica under Sulfate Attack. Adv. Civ. Eng. 2018, 1-11. https://doi.org/10.1155/2018/2715474

Varghese, L., Rao, V.V.L.K., Parameswaran, L., 2019. Nanosilica-added concrete: strength and its correlation with time-dependent properties. Proc. Inst. Civ. Eng. - Constr. Mater. 172, 85-94. https://doi.org/10.1680/jcoma.17.00031 
Wang, X.F., Huang, Y.J., Wu, G.Y., Fang, C., Li, D.W., Han, N.X., Xing, F., 2018. Effect of nano-SiO2 on strength, shrinkage and cracking sensitivity of lightweight aggregate concrete. Constr. Build. Mater. 175, 115-125. https://doi.org/https://doi.org/10.1016/j.conbuildmat.2018.04.113

Wasan, D., Nikolov, A., Moudgil, B., 2005. Colloidal dispersions: Structure, stability and geometric confinement. Powder Technol. 153, 135-141. https://doi.org/https://doi.org/10.1016/j.powtec.2004.12.005

Yu, Q.L., Spiesz, P., Brouwers, H.J.H., 2015. Ultra-lightweight concrete: Conceptual design and performance evaluation. Cem. Concr. Compos. 61, 18-28. https://doi.org/https://doi.org/10.1016/j.cemconcomp.2015.04.012

Zhang, M.-H., Islam, J., 2012. Use of nano-silica to reduce setting time and increase early strength of concretes with high volumes of fly ash or slag. Constr. Build. Mater. 29, 573-580. https://doi.org/https://doi.org/10.1016/j.conbuildmat.2011.11.013

Zhang, M.-H., Islam, J., Peethamparan, S., 2012. Use of nano-silica to increase early strength and reduce setting time of concretes with high volumes of slag. Cem. Concr. Compos. 34, 650-662. https://doi.org/https://doi.org/10.1016/j.cemconcomp.2012.02.005

Zhang, P., Xie, N., Cheng, X., Feng, L., Hou, P., Wu, Y., 2018. Low dosage nano-silica modification on lightweight aggregate concrete. Nanomater. Nanotechnol. 8, 184798041876128. https://doi.org/10.1177/1847980418761283 